\title{
CHANNEL ALLOCATION FOR DIRECT SEQUENCE SPREAD SPECTRUM USING VERTEX MERGE ALGORITHM
}

\author{
Handrizal $^{1}$, Noraziah Ahmad ${ }^{2}$, Ahmed N Abd. Alla ${ }^{3}$ \\ ${ }^{1,2}$ Faculty of Computer Systems \& Software Engineering \\ University Malaysia Pahang \\ Lebuhraya Tun Razak, 26300 Gambang, Kuantan, Malaysia \\ ${ }^{3}$ Faculty of Electrical \& Electronics Engineering \\ University Malaysia Pahang \\ Lebuhraya Tun Razak, 26300 Gambang, Kuantan, Malaysia \\ Corresponding author:handrizal_tanjung@yahoo.com
}

\begin{abstract}
This paper presents a new algorithm namely Vertex Merge Algorithm(VMA) for channel allocation in Direct Sequence Spread Spectrum(DSSS). VMA try to solve channel allocation based on graph theory. Results from the simulation study reveal that the new graph model can provide reduce the channel required.
\end{abstract}

\section{KEYWORDS}

Graph Colouring, Vertex Merge, Spread Spectrum, DSSS, Channel Allocation.

\section{INTRODUCTION}

The spectacular development of network and internet has a big impact to the companies in various types and sizes. The advanced wireless technologies support the development of network, internet and intranet capability for the mobile workers, isolated area and temporary facilities. Wireless networking expand and increase the capability of computer networking. The new technologies enable the wireless networking as one of access in higher velocity and qualified for the computer network and internet.

Wireless local area networks (WLANs) have gained importance in the recent years as an Internet-access technology. As competition has driven down costs of WLAN equipment, wireless Internet access mechanisms are increasingly available in numerous public hot spots like coffee-shops, airports, and hotels. Today numerous public places such as airports, cafeterias, and even complete city centers are equipped with numerous access points (APs) to offer almost ubiquitous wireless connectivity. At the same time the increased density of WLAN access points has started to highlight the negative effects or shortcomings of the original IEEE 802.11 standards. Most importantly, no standard channel allocation method exists for WLAN access points. This has lead to the situation where large majority of APs is using default channel settings, leading to highly inefficient use of the already crowded spectrum in the ISM bands. This situation is especially critical in the $2.4 \mathrm{GHz}$ band, due to the small number of nonoverlapping WLAN channels available, and coexistence problems with several other wireless technologies.

ISM bands are unlicensed frequency bands [1]. These bands can be used freely and therefore there is only a slight control over them, so when selecting a channel to build a WLAN it is can 
expect that other devices may be using it. Although different spread spectrum techniques are defined (DSSS or FHSS) in order to minimize the effect of interferences and although the legal limits for low power transmissions are respected, the coexistence of different types of devices in nearby channels can seriously degrade the performance of a WLAN.

The problem gets worst in the $2.4 \mathrm{GHz}$ ISM band, where according to European regulatory bodies, 13 channels are defined, whose carriers go from 2.412 (channel 1), to $2.472 \mathrm{GHz}$ (channel 13), see Figure 1. Consecutive carriers are spaced $5 \mathrm{MHz}$, whereas the spread signal bandwidth is about $24 \mathrm{MHz}$, so it is only have as much as three non-overlapping channels (e.g. 1,6 and 11). It seems clear that in regions with a great density of nodes, three channels shall not be enough.

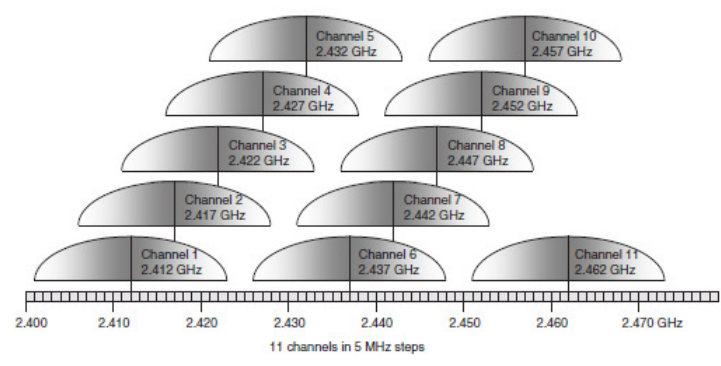

Figure 1: DSSS channel allocation

With the common DSSS technology, only three non-overlapping channels are available, see Figure 2 [2], and no standard mechanism exists for the access points to dynamically select the channel to be used as to minimize interference with other APs.

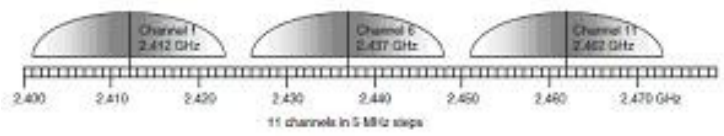

Figure 2: DSSS non-overlapping channels

To use DSSS systems with overlapping channel (e.g., channel 1 and 2) in the same physical space would cause interference between the systems. DSSS systems using overlapping channel should not be co-located because there will almost always be a drastic or complete reduction in throughput. Because the center frequencies are $5 \mathrm{MHz}$ apart, and the center frequencies for nonoverlapping channels must be at least $25 \mathrm{MHz}$ apart, channel should be co-located only if the channel numbers are at least five apart.

Several research articles have been published regarding allocation channel. Among them were those by Al Mamun et al.[3], Chen et al.[4], Duan et.al[5], Mahonen et al.[6], Malone et al.[7], Ming, H. et.al[8], Juhos[9] Raj[10], Riihijarvi et al.[11,12], Yuqing et.al[13], Yue et.al[14], and Zhuang et.al[15]. Those articles revealed that channel allocation for DSSS is one of the current issues that still unsolved in channel allocation. Therefore, the study on this basis in initiated.

One of the simplest algorithms is namely Welsh Powell algorithm. This algorithm has been proposed for time table schedule. This algorithm determines the channel base on high degree of access points. It not always provides the minimum number of colours required to access point. This algorithm is enough practice for simple graph. However, this algorithm is not enough practice for complex graph. 
Another algorithm, call Degree of Saturation (Dsatur) algorithm became popular because they are flexible and are easily implemented. This algorithm has been applied for frequency allocation. This algorithm determines the channel base on high degree of saturation. It is enough practice for simple graph and complex graph. However, this algorithm still requires that a bigger number of channel in complex graph.

\section{Colouring in CHANNEl allocation}

In this section it is shall formulate the channel allocation problem for DSSS in terms of graphtheoretic colouring problem. First it is recall shortly the statement of the colouring problem based on graph theory [16] that is of interest in the channel allocation context.

Suppose it is are given a simple graph $G=(V, E)$, that is, a graph consisting of a set of vertices $\mathrm{V}$, and set of edges $\mathrm{E}$ connecting the vertices so, that loops (edges connecting a vertex to itself) and multiple edges between vertices are not allowed. Then a vertex colouring of $\mathrm{G}$ is a map: $\mathrm{V}$ $(\mathrm{G}) \rightarrow \mathrm{F}$, where $\mathrm{F}$ is a set of colours, usually some small subset of positive integers. It is shall call a colouring admissible, if $\mathrm{C}(\mathrm{Vi})_{-}=\mathrm{C}(\mathrm{Vj})$ for all adjacent $\mathrm{Vi}$ and $\mathrm{Vj}$ (that is, for those vertices connected by an edge). It is call an admissible colouring minimizing $|\mathrm{C}(\mathrm{V})|$ an optimal colouring. The number of colours used by the optimal colouring is called the chromatic number of the graph.

\subsection{Interference graphs}

It is shall now formulate the channel allocation problem in terms of the terminology introduced in the previous section. Given a collection $\left\{\mathrm{v}_{\mathrm{i}}\right\}$ of access points, it is shall form an interference graph $G=\left(V_{G}, E_{G}\right)$ as follows. The vertex set $V$ is simply identified with the set $\left\{v_{i}\right\}$. The set of edges $\mathrm{E}$ is constructed as the union of those pairs $\left\{\mathrm{v}_{\mathrm{k}}, \mathrm{v}_{\mathrm{l}}\right\}$ of vertices, that correspond to access points $\mathrm{v}_{\mathrm{k}}$ and $\mathrm{v}_{\mathrm{l}}$ that would interfere with each other's radio traffic should they be assigned to use the same channel. Finally, it is let F, the set of "colours", to be the collection of channels available to the access points. Now the channel allocation problem is simply finding of an admissible colouring of $G$ with the colour set $F$. It is shall call a colouring admissible, if $\mathrm{C}\left(\mathrm{v}_{\mathrm{i}}\right)=\mathrm{C}\left(\mathrm{v}_{\mathrm{j}}\right)$ for all adjacent $\mathrm{v}_{\mathrm{i}}$ and $\mathrm{v}_{\mathrm{j}}$ (that is, for those vertices connected by an edge). It is call an admissible colouring minimizing $\{\mathrm{C}(\mathrm{v})\}$ an optimal colouring.

Naturally the size of the colour set is greatly technology and legislation dependent. In most European countries, $F=\{1,2 \ldots 13\}$ for DSSS technologies, of which the subset $F^{\prime}=\{1,6,11\}$ corresponds to the non-overlapping channels.

\subsection{Adjacency Matrix}

Suppose $\mathrm{G}$ is a graph with $\mathrm{m}$ vertices, and suppose the vertices have been ordered, say, $\mathrm{v}_{\mathrm{i}}, \mathrm{v}_{\mathrm{j}}, \ldots$, $\mathrm{v}_{\mathrm{m}}$. Then the adjacency matrix $\mathrm{A}(\mathrm{G})=\left[\mathrm{a}_{\mathrm{ij}}\right]$ of the graph $\mathrm{G}$ is the $\mathrm{m} \times \mathrm{m}$ matrix defined by:

$$
a_{i j}=\left\{\begin{array}{l}
1, \text { if } \mathrm{v}_{\mathrm{i}} \mathrm{v}_{\mathrm{j}} \in \mathrm{E}_{\mathrm{G}} \\
0, \text { if } \mathrm{v}_{\mathrm{i}} \mathrm{v}_{\mathrm{i}} \notin \mathrm{E}_{\mathrm{G}}
\end{array}\right.
$$


Figure 3 shows a graph and its matrix adjacent.

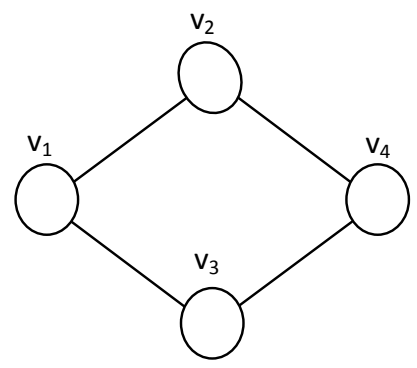

\begin{tabular}{l|llll}
\multicolumn{1}{c}{} & $\mathrm{v}_{1}$ & $\mathrm{v}_{2}$ & $\mathrm{v}_{3}$ & $\mathrm{v}_{4}$ \\
\cline { 2 - 5 } $\mathrm{v}_{1}$ & 0 & 1 & 1 & 0 \\
$\mathrm{v}_{2}$ & 1 & 0 & 0 & 1 \\
$\mathrm{v}_{3}$ & 1 & 0 & 0 & 1 \\
$\mathrm{v}_{4}$ & 0 & 1 & 1 & 0
\end{tabular}

Figure 3: Graph G with the matrix adjacent

The adjacency matrix $A$ of a graph $\mathrm{G}$ does depend on the ordering of the vertices of $\mathrm{G}$, that is, a different ordering of the vertices yields a different adjacency matrix. However, any two such adjacency matrices are closely related in that one can be obtained from the other by simply interchanging row and columns. On the other hand, the adjacency matrix does not depend on the order in which the edges (pairs of vertices) are input into the computer.

\section{THE PROPOSED MODEL}

The problem of approximate vertex colouring is a much studied one and the number of available algorithms is vast. After considerable review effort it is decided to create a new algorithm which it is call the Vertex Merge algorithm (VMA). The algorithm is fundamentally deterministic, as opposed to many randomised algorithms proposed. This is necessary as the access points must naturally agree on the channels allocated.

Let us now have a closer look at the vertex merge algorithm. It belongs to the family of Welsh Powell algorithms, that is, it is using some heuristic method to select a vertex to be coloured, which it then colours using the first colour consistent with the colouring problem statement. The heuristic used by the vertex merge algorithm is to find the subset of vertices with highest "degree", that is, the vertices with largest number of differently edge neighbours. If this subset contains only one vertex, it is chosen to be coloured. If more vertices remain in the set, the selection is then made (within the subset of maximal degree) in the order of decreasing number of uncoloured neighbours.

\subsection{Algorithm}

The following is a step by step VMA.

1. Arrange the vertex by decreasing order of degrees.

2. Choose the first uncoloured vertex from the set.

3. Colour the chosen vertex with the least possible colour.

4. Merge the vertex with the first non-adjacent vertex.

5. Colour the chosen vertex with the same colour. If there is no more non-adjacent vertex, return to step 2.

6. If the entire vertex are coloured, stop. Otherwise, return to Step 2. 
International Journal of Computer Science \& Information Technology (IJCSIT), Vol 3, No 1, Feb 2011

\subsection{Example}

We demonstrate the steps of the algorithm with a small example. The input graph is shown below in figure 4 with $n=7$ vertices labeled $V=\{1,2,3,4,5,6,7\}$. The algorithm required 2 colouring of the vertices using the set of colors $\{1,2\}$ represented by red and green respectively.

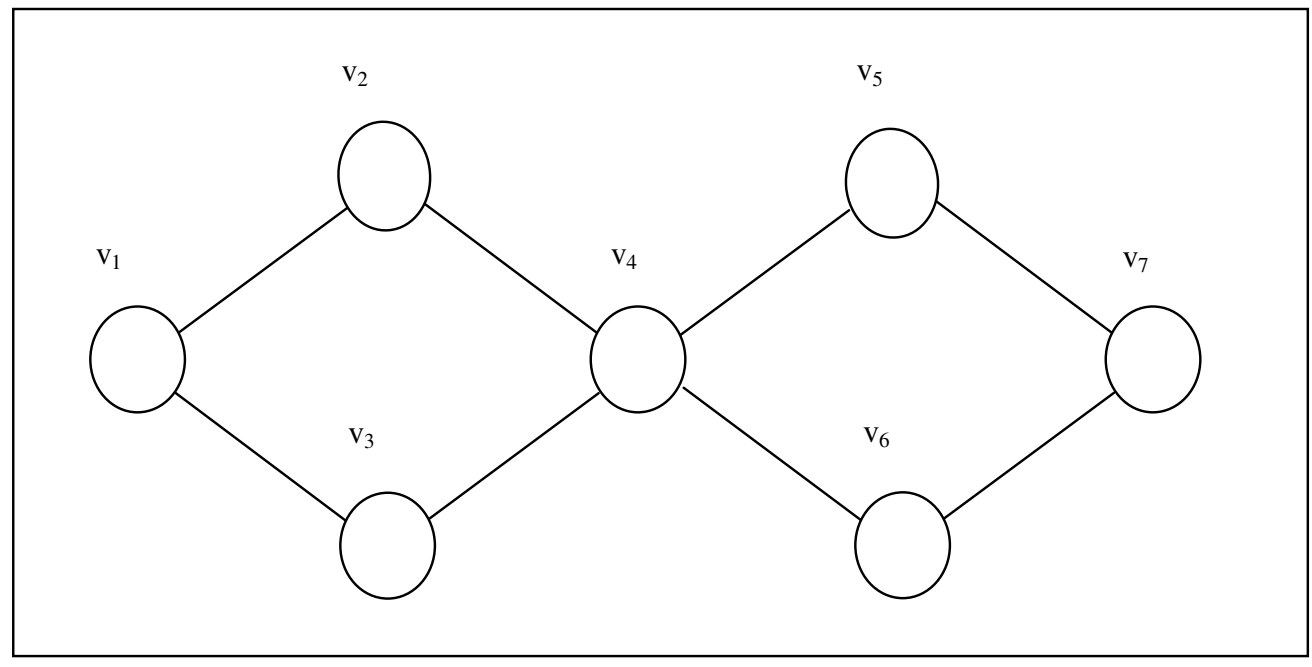

Figure 4: Example graph

1) Sorting the uncolored vertex which have the highest degree. Vertex with highest degree is $\mathrm{v}_{4}$ (which 4 edge) then $\mathrm{v}_{1}, \mathrm{v}_{2}, \mathrm{v}_{3}, \mathrm{v}_{5}, \mathrm{v}_{6}, \mathrm{v}_{7}$ each with 2 degree. Then the sequence is $\left\{\mathrm{v}_{4}, \mathrm{v}_{1}\right.$, $\left.\mathrm{v}_{2}, \mathrm{v}_{3}, \mathrm{v}_{5}, \mathrm{v}_{6}, \mathrm{v}_{7}\right\}$.

2) Choose the first uncoloured vertex from the set. This causes vertex $v_{4}$ to be coloured with colour 1 .

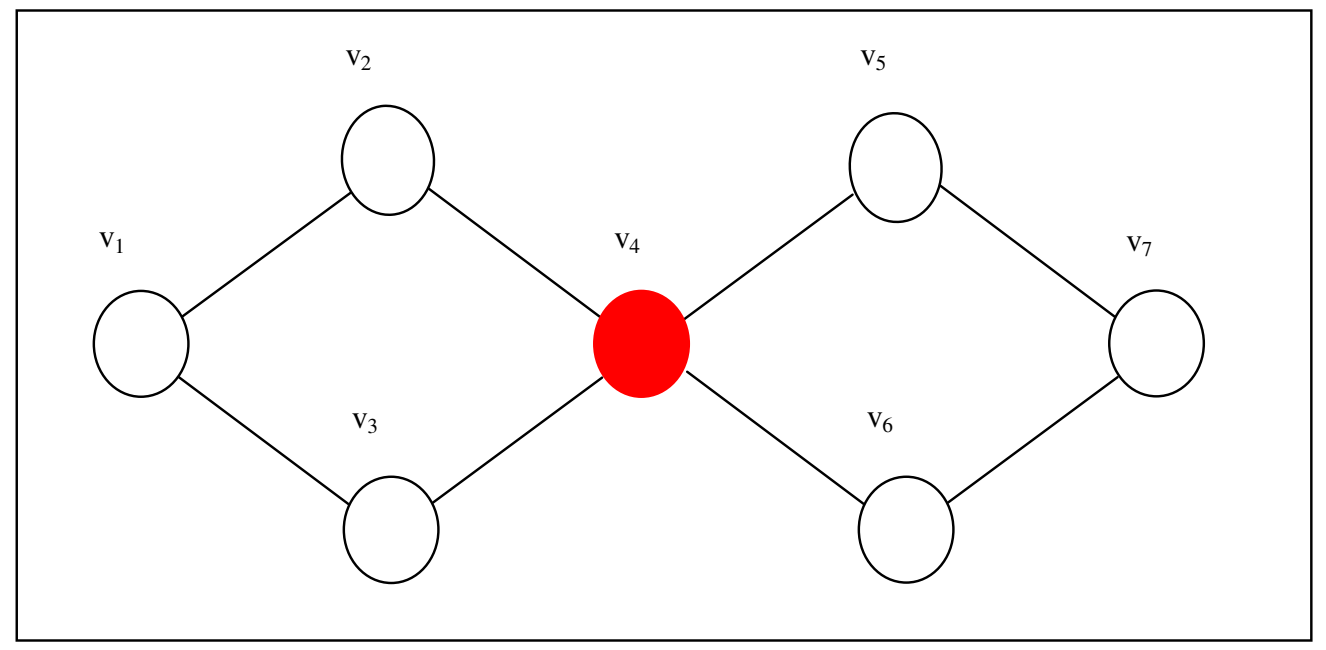

Figure 5: Example graph with second step VMA 
International Journal of Computer Science \& Information Technology (IJCSIT), Vol 3, No 1, Feb 2011

3) Merge with the first non-neighbour hyper-node, in this case the vertex are not adjacent with $\mathrm{v}_{4}$ are $\mathrm{v}_{1}$ and $\mathrm{v}_{7}$. Thus that the $\mathrm{v}_{4}$ merger into $\mathrm{v}_{1}$ and $\mathrm{v}_{4}$. Then $\mathrm{v}_{1}$ and $\mathrm{v}_{7}$ same colour with $\mathrm{v}_{4}$.

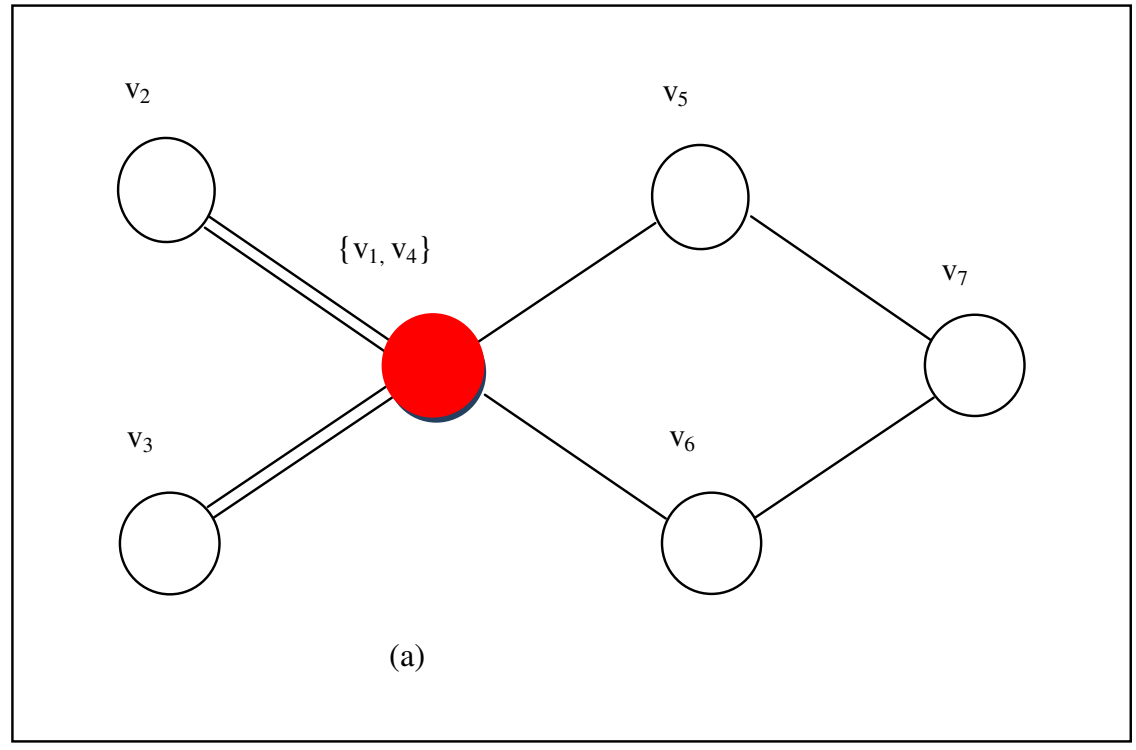

Figure 6 (a): Example graph with third step VMA

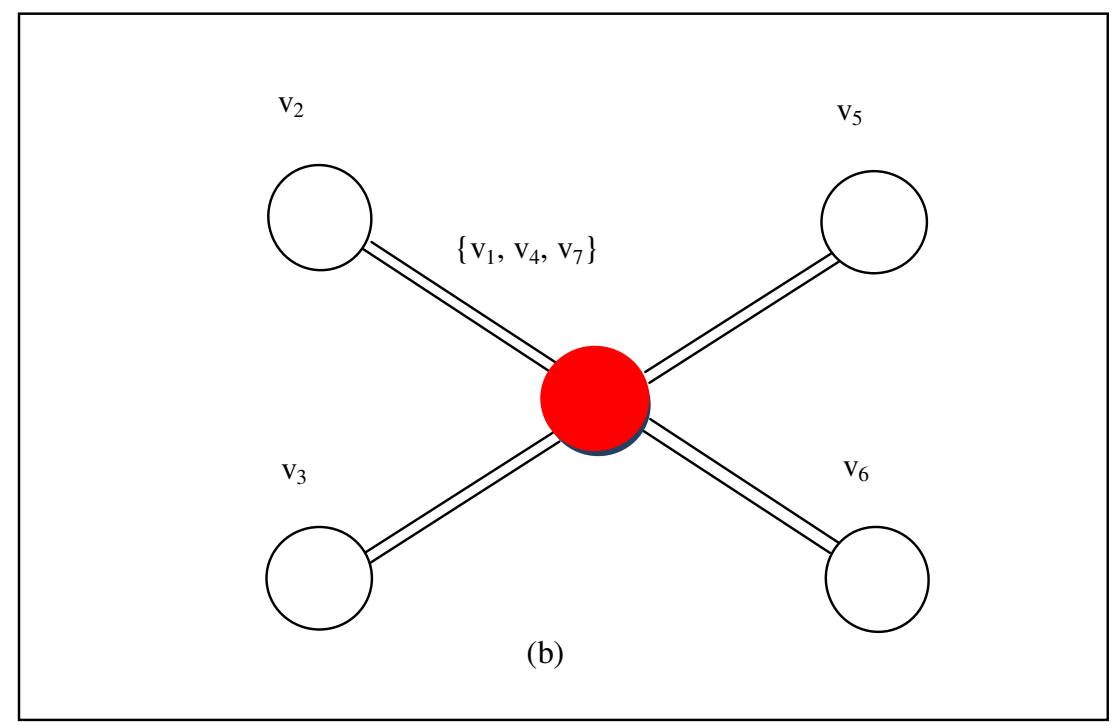

Figure 6 (b): Example graph with third step VMA

4) If there exists an uncolored vertex then continue with Step 2.

a) Now sequence uncoloured vertex which have the highest degree is $\left\{\mathrm{v}_{2}, \mathrm{v}_{3}, \mathrm{v}_{5}, \mathrm{v}_{6}\right\}$.

b) Choose the first uncolored vertex from the set. This causes vertex $v_{2}$ to be coloured with colour 2. 


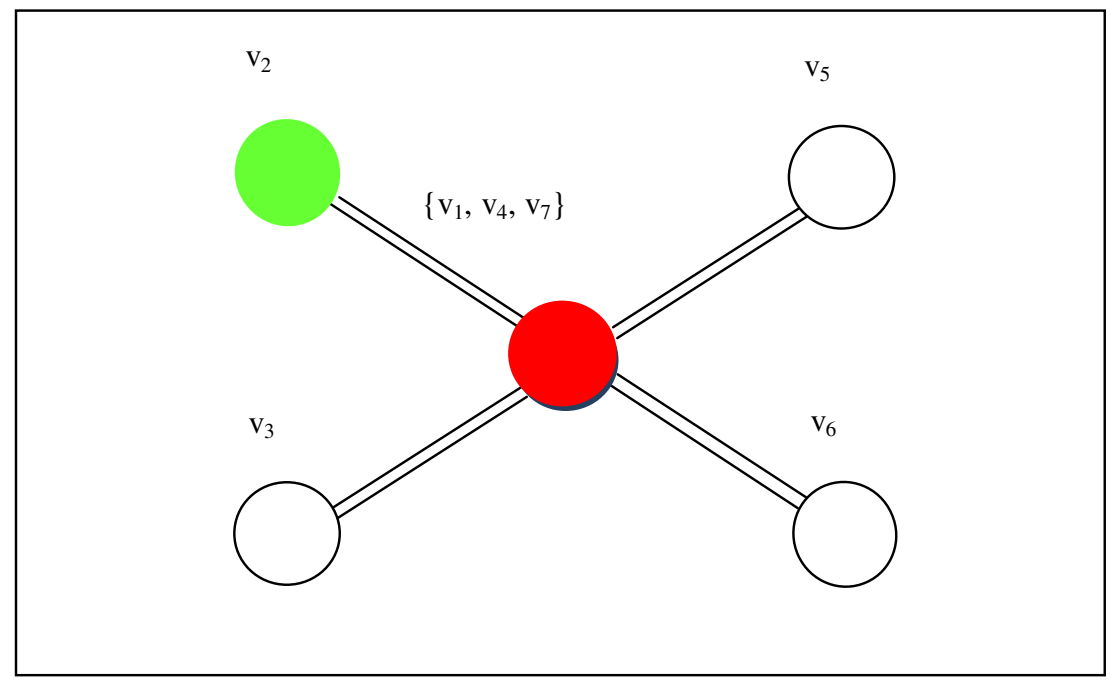

Figure 7: Example graph with fourth step VMA

c) Merge with the first non-neighbour hyper-node, in this case the vertex are not adjacent with $\mathrm{v}_{2}$ are $\mathrm{v}_{3}, \mathrm{v}_{5}$ and $\mathrm{v}_{6}$, so that the $\mathrm{v}_{2}$ merger into $\mathrm{v}_{3}, \mathrm{v}_{5}$ and $\mathrm{v}_{6}$. Then $\mathrm{v}_{3}, \mathrm{v}_{5}$ and $\mathrm{v}_{6}$ same colour with $\mathrm{v}_{2}$.

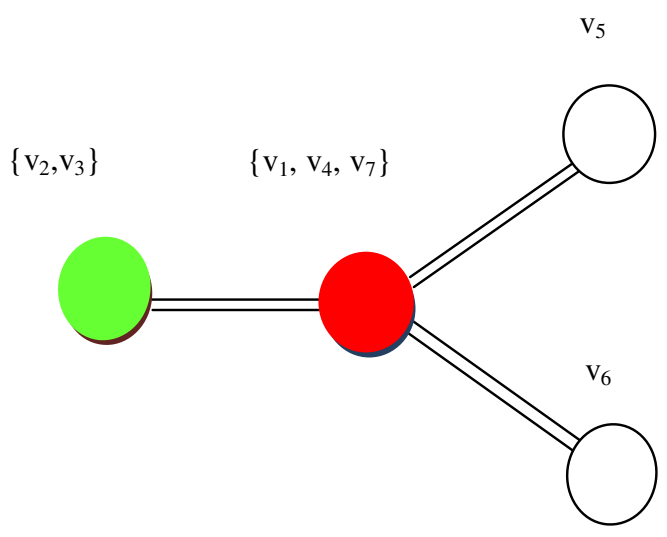

(a)

Figure 8 (a): Example graph with fifth step VMA 


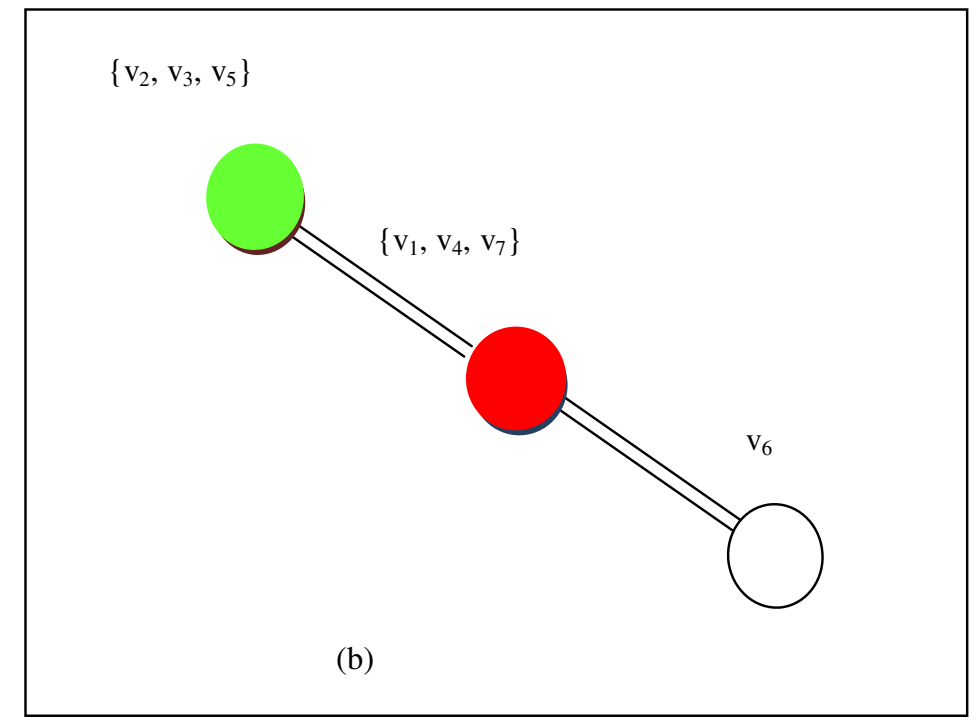

Figure 8 (b): Example graph with fifth step VMA

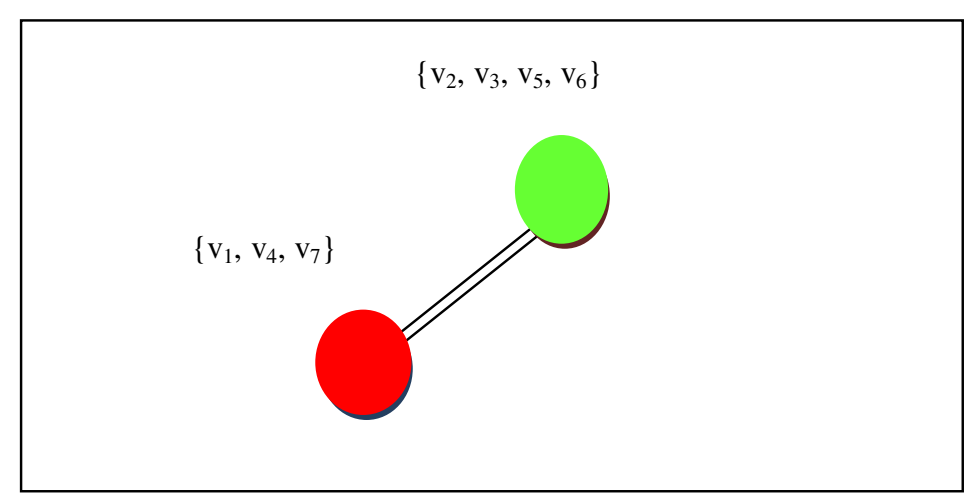

Figure 9: Example graph with last step VMA

5) If all vertices are coloured, thus the algorithm terminates, and the final colouring is given by $\mathrm{C}\left(\mathrm{v}_{1}\right)=1, \mathrm{C}\left(\mathrm{c}_{2}\right)=2, \mathrm{C}\left(\mathrm{v}_{3}\right)=2, \mathrm{C}\left(\mathrm{v}_{4}\right)=1, \mathrm{C}\left(\mathrm{v}_{5}\right)=2, \mathrm{C}\left(\mathrm{v}_{6}\right)=2, \mathrm{C}\left(\mathrm{v}_{7}\right)=1$. Finally, $\mathrm{V}_{\mathrm{G}}$, is coloured using the smallest colour that is chromatic number is 2 .

Of course the number of colours needed to solve the vertex colouring problem for the interference graph is of great interest. This is especially important in the case of DSSS, as the number of colours available is only three, supposing that it is want usage only non-overlapping channels. From the example graph, it is required 2 colour for colouring the graph. It means that required 2 channels for DSSS, that is channel 1 and channel 6.

\section{RISULT AND DISCUSSION}

In this section it is simulation the VMA with input tree graph that is graph1 with number of vertex 7, graph2 with number of vertex 8 and graph3 with number of vertex 7 . In the each graph, vertex equal the access point (AP). Table 1 shows input example graph for simulation. 
International Journal of Computer Science \& Information Technology (IJCSIT), Vol 3, No 1, Feb 2011

Table 1: Input graph for simulation

\begin{tabular}{|c|c|c|}
\hline \multirow[t]{2}{*}{ No. } & \multicolumn{2}{|c|}{ Input } \\
\hline & Adjacent matrix & Graph \\
\hline 1 & $\begin{array}{llllllll}0 & 1 & 1 & 0 & 0 & 0 & 0 \\
1 & 0 & 0 & 1 & 0 & 0 & 0 \\
1 & 0 & 0 & 1 & 0 & 0 & 0 \\
0 & 1 & 1 & 0 & 1 & 1 & 0 \\
0 & 0 & 0 & 1 & 0 & 0 & 1 \\
0 & 0 & 0 & 1 & 0 & 0 & 1 \\
0 & 0 & 0 & 0 & 1 & 1 & 0\end{array}$ & \\
\hline 2 & $\begin{array}{lllllllll} & 0 & 1 & 0 & 1 & 0 & 0 & 0 & 0 \\
1 & 0 & 1 & 0 & 1 & 0 & 0 & 0 \\
0 & 1 & 0 & 0 & 1 & 1 & 1 & 0 \\
1 & 0 & 0 & 0 & 1 & 0 & 0 & 1 \\
0 & 1 & 1 & 1 & 0 & 1 & 0 & 1 \\
0 & 0 & 1 & 0 & 1 & 0 & 1 & 0 \\
0 & 0 & 1 & 0 & 0 & 1 & 0 & 0 \\
0 & 0 & 0 & 1 & 1 & 0 & 0 & 0\end{array}$ & \\
\hline 3 & $\begin{array}{lllllll} & 1 & 1 & 0 & 0 & 1 & 0 \\
1 & 0 & 1 & 0 & 0 & 0 & 0 \\
1 & 1 & 0 & 1 & 0 & 1 & 0 \\
0 & 0 & 1 & 0 & 1 & 0 & 0 \\
0 & 0 & 0 & 1 & 0 & 1 & 1 \\
1 & 0 & 1 & 0 & 1 & 0 & 1 \\
0 & 0 & 0 & 0 & 1 & 1 & 0\end{array}$ & \\
\hline
\end{tabular}


International Journal of Computer Science \& Information Technology (IJCSIT), Vol 3, No 1, Feb 2011

The simulation result from the input graph in table 1 can be shows in table 2 .

Table 2: Simulation Result VMA

\begin{tabular}{|l|l|}
\hline No. & $\begin{array}{l}\text { Number of channel } \\
\chi(\mathrm{G})=2 \\
\mathrm{C}(1,4,7)=1 \\
\mathrm{C}(2,3,5,6)=6\end{array}$ \\
\hline 1
\end{tabular}


From the table simulation results of the three graphs can be seen that,

1. For the first graph with the number vertex 7, needed colour as much as 2 colour for colouring the graph. It means that required 2 channels in DSSS for this case, that is:

- channel 1 for $\mathrm{AP}_{1}, \mathrm{AP}_{4}$ and $\mathrm{AP}_{7}$

- channel 6 for $\mathrm{AP}_{2}, \mathrm{AP}_{3}, \mathrm{AP}_{5}$ and $\mathrm{AP}_{6}$

2. For the second graph with the number vertex 8 , needed colour as much as 3 colour for colouring the graph. It means that required 3 channels in DSSS for this case, that is:

- channel 1 for $\mathrm{AP}_{1}, \mathrm{AP}_{5}$ and $\mathrm{AP}_{7}$

- channel 6 for $\mathrm{AP}_{3}$ and $\mathrm{AP}_{4}$

- channel 11 for $\mathrm{AP}_{2}, \mathrm{AP}_{6}$ and $\mathrm{AP}_{8}$

3. For the third graph with the number vertex 7, needed colour as much as 3 colour for for colouring the graph. It means that required 3 channels in DSSS for this case, that is:

- channel 1 for $\mathrm{AP}_{3}$ and $\mathrm{AP}_{5}$

- channel 6 for $\mathrm{AP}_{2}, \mathrm{AP}_{4}$ and $\mathrm{AP}_{6}$

- channel 11 for $\mathrm{AP}_{1}$ and $\mathrm{AP}_{7}$

\section{CONCLUSIONS}

In this paper, it is introduced a new graph model which it is call the Vertex Merge Algorithm (VMA) for channel allocation problems on Direct Sequence Spread Spectrum. The problem of minimising the number of channels needed to eliminate interference is a graph colouring problem. Results from the simulation study reveal that the new graph model can provide reduce the channel needed. It is forms a good basis for developing efficient graph colouring algorithms, because of its aims to reduce the colour needed for channel allocation on Direct Sequence Spread Spectrum.

\section{REFERENCES}

[1] T. Rappaport, Wireless Communications: Principle and Practice, Prentice Hall, 2002.

[2] Handrizal, Noraziah Ahmad,Ahmad N Abda Alla, Comparison Between Direct Sequence Spread Spectrum (DSSS) And Frequency Hopping Spread Spectrum (FHSS), in proceedings of ICSECS'09, vol. 1, October 2009.

[3] Al Mamun, K.M.A. et.al. An Efficient Variable Channel Allocation Technique for WLAN IEEE 802.11 Standard, in Proceedings Conference on Circuits, Communication and System, pp.92-95. 2009.

[4] Chen, J. et.al. A Fast Channel Allocation Scheme Using Simulated Annealing in Scalable WLANs. IEEE International Conference on Broadband Communications, Networks and System, pp.205-211. 2008.

[5] Duan, Z. et.al. Optimal Channel Assignment for Wireless Networks Modelled as Hexagonal and Square Grids. International Conference on Networks Security Wireless Communications and Trusted Computing.2010.

[6] Mahonen, P. et.al. Automatic Channel Allocation for Small Wireless Local Area Networks Using Graph Colouring Approach. $15^{\text {th }}$ IEEE International Symposium on Personal, Indoor and Mobile Radio Communications. Vol.1, pp.536-539. 2004.

[7] Malone, D., et.al. Experimental Implementation of Optimal WLAN Channel Selection without Communication. $2^{\text {nd }}$ IEEE International Symposium on New Frontiers in Dynamic Spectrum Access Networks, pp.316-319. 2007.

[8] Ming, H. et.al. Hierarchical genetic algorithm for dynamic channel units allocation in tdcdma/tdd system. International Journal of Wireless \& Mobile Networks (IJWMN), Vol 1, No 2. pp.103-116. 2009 
International Journal of Computer Science \& Information Technology (IJCSIT), Vol 3, No 1, Feb 2011

[9] Juhos and Jano I. Van Hemert, Increasing the efficiency of graph colouring algorithms with a representation based on vector operations. Journal of software, vol. 1, No. 2 August, 2006.

[10] Raj, S. B.E. and Jacob, J.S. Optimal Channel Allocation in Wireless LAN, IEEE International on Wireless and Optical Communication Networks. 2006.

[11] Riihijarvi, J. et.al. Frequency allocation for WLANs Using Graph Colouring techniques, in Proceedings of second annual conference of WONS'05. 2005.

[12] Riihijarvi, J. et.al. Performance Evaluation of Automatic Channel Assignment Mechanism for IEEE 802.11 Base on Graph Colouring, in Proceedings The $17^{\text {th }}$ Annual IEEE International Symposium on Personal, Indoor and Mobile Communications, pp.1-5. 2006.

[13] Yuqing, L. et.al. An Improved Channal Allocation Algorithm Based on List-coloring. International Conference on Wireless Communications Networking and Mobile Computing. 2010 .

[14] Yue, X. et.al. A Distributed Channel Assignment Algorithm for Uncoordinated WLANs. IEEE on Consumer Communications and Networking Conference. 2010.

[15] Zhuang, X. et.al. Channel Assignment in Multi-Radio Wireless Networks Based on PSO Algorithm. International Conference on Future Information Technology. 2010.

[16] Diestel, R. Graph Theory. Springer-Verlag, 2010. 